\title{
INTEREST AND READING MOTIVATION
}

\author{
Alhamdu \\ Lectrurer of Islamic Psychologhy Program \\ Ushuluddin and Islamic Thinking Faculty of UIN Raden Fatah Palembang \\ alhamdu@ymail.com \\ alhamdu_uin@radenfatah.ac.id
}

\begin{abstract}
The purpose of this study is to examine the relationship between interest and reading motivation based on literature review. The concept of the interest portrayed as a psychological state that occurs during interaction between individual and specific topic, object or activity including process of willingness, increased attention, concentration and positive feeling to the topic, object or activity. Meanwhile reading motivation emphasized to mental readiness, willingness and refers to beliefs and perception of individual to engage in reading activity.

Some researchers were identified factors that influenced reading motivation such as intrinsic and extrinsic factors, self-concept and value of reading, and interest. In general, the literature review described that have positive relationship between interest and reading motivation. Keywords: Interest, reading motivation, psychological state.

\section{Introduction}

Reading is one important think for everyone. Reading is also as a gateway for getting success, because it can open and provide new insights. Many new things will find in a reading. The things maybe did not know, or even things that previously never imagined, perhaps will find in reading. Further, reading also as a facility for getting and developing intellectual, spiritual, emotional, and self-confidence of individual. It means, reading will open many opportunities to absorb as much knowledge that is useful in life. Simultaneously, reading also will develop ability to think creatively, critically, analytically and imaginatively. Therefore, Aksan \& Kisac (2009) stated that reading as a fundamental of learning that helping individual for getting knowledge, because reading activity will shape the ability to think through the processes of capturing

ideas or information, comprehend, imagine, implement and expression (Aksan \& Kisac, 2009).

Furthermore, reading is assuming as a tour of mind, because reading able to provide pleasure and enjoyment of the soul. Through reading, reader can go anywhere to see other world without being limited by dimension of space and time. Reading really will give opportunities to imagine anything in life. Therefore, Grayling as cited on Manguel (1997) mentioned reading as a flight. Grayling described that when individual was flight, he/she will view over wide of terrains, human variety, ideas, shared experiences and the fruits of many inquiries (Manguel, 1997). Those are some reason, why people sometime can spend their time and their money to do reading activity. However, also not everyone can spend their time and their money to do reading activity. So, why it's happen?
\end{abstract}




\section{Problem Statement}

As I mentioned above, reading is as a bridge for achieving improvement. It means, reading plays one important role for individual or even society to get success in life, because one success requirements are concerning to information. Information is relating to knowledge. When individual have much information, it referred that the individual have wider knowledge. Conversely, when individual have lack information, it referred that the individual have little knowledge. So, when individual does not enough knowledge, how individual can compete and survive in their life. Therefore, reading plays one important think and also as a key for opening all the door of information.

According to Valleley \& Shriver (2003) and Strommen \& Mates (2004), reading as a primary learning objective for students in the early stages of formal education (Strommen \& Mates, 2004; Valleley \& Shriver, 2003). Furthermore, Valleley \& Shriver (2003) mentioned that students who having strong reading have tendency to get success in their study, particularly in subject areas mathematics, social studies and science (Valleley \& Shriver, 2003). That argument also supported by Cok and Guthrie (2001) who stated that reading as an important way to enhance both of academic and social development of students (Cox \& Guthrie, 2001). All of those arguments described that how important the reading in educational setting.

Gambrell \& Marinak (2008) and Guthrie, Wigfield, \& VonStecker (2000) stated that the motivation plays the important role in reading. Students who have strong motivation to do reading can spend their time so much in reading activity. Meanwhile, students who lack motivation to do reading will try to avoid reading activity. Moreover, Gambrell \& Marinak (2008) and Guthrie et al
(2000) also described that motivation as a key for doing reading activity (Guthrie, Wigfield, \& VonSecker, 2000; Marinak \& Gambrell, 2008). Without motivation to read, students may never reach their full potential in their learning. Further, Guthrie et al (2007) also mentioned that reading motivation influenced by motivation constructs such as interest, perceived control, collaboration, involvement, and efficacy (Guthrie, et al., 2007).

Moreover, Aksan \& Kisac (2009), Guthrie et al (2007) and Hidi \& Renninger (2006) described interest as a positive feeling of individual including engagement, attention, concentration, happiness and willingness to spent more time to do activity. They also mentioned that interest is one important think in learning, because interest as a gateway for increasing students performance in learning (Aksan \& Kisac, 2009; Guthrie, et al., 2007; Hidi \& Renninger, 2006). However, only few studies were conducted on both variables of interest and reading motivation. Therefore, in this study I would like to examine the relationship between interest and reading motivation based on literature review, because both of those variables have the big impact to increase learning performance of students.

\section{The Concept of Interest}

Interest has a big impact on student learning and performance. Dewey (1913) as cited on Tin (2006), and Ainley et al (2002) stated that interest plays an essential and necessary role in learning. It means, student could be difficult to follow the learning activities when they don't have interest (Ainley, Hillman, \& Hidi, 2002; Tin, 2006). Meanwhile, Alexander \& Wade (2000) and McWhaw \& Abrami (2001) explained that the interest will greatly affect students' in learning process and learning activity. The student who is not interested to learning process and learning activity, perhaps would have a 


\section{3}

tendency to not learn as well as possible, and eventually will influence quality of learning, because when students have interest students will prepare themselves as well in learning (Alexander \& Wade, 2000; McWhaw \& Abrami, 2001). So, when student interested to learning activities, perhaps students will be show appropriate behavior such as more attention, more active, and more engage in activities that supported to the learning.

Basically, interest refers to inner tendency of individual. Pintrich (1989) and Schiefele (1991) as cited in McWhaw \&Abrami (2001), Pintrich \& Schunk (1996) and Schiefele \& Krapp (1996) defined interest as a positive feeling about the topics, subject area or activities. So, in this meaning interest could be express with happy or not happy when student doing something or do they activities (McWhaw \& Abrami, 2001; Pintrich \& Schunk, 1996; Schiefele \& Krapp, 1996). Meanwhile, krapp (2002), Renninger et al (2002), Hidi \& Renninger (2006) and Hidi (2006) described interest as a unique motivational variable and as a psychological state that occurs during interaction between individual and objects or activity that their interest. In this interaction including a process of willingness to engage on specific object or activity, and in this process also characterized by increased attention, concentration and positive affects to the object or activity (Hidi, 2006; Hidi \& Renninger, 2006; Krapp, 2002; Renninger, Ewen, \& Lasher, 2002). It means, interest in this context could be seen from student participation in specific object or activity. When student were interested to specific object or activity, student will show more active participation including attention, concentration and happiness to the object or activity.

Based on explanation above, writer concluded interest as a positive feeling including engagement, attention, concentration, happiness and willingness to spend more time to specific object or activity.

\section{The Kinds of interest}

Interest is not innate or natural, but interest grows and evolves based on individual ages and experiences. Krapp (2002) explained that interest grew and developed based on relationship between individual purpose and environmental factor. Further, Krapp (2002) distinguished interest in two parts, there are; subjective interest and objective interests. Subjective interest refers to associated feelings toward experiences, including expectation to pleasant or unpleasant in specific object or activity. Meanwhile, objective interest refers to positive reaction of environment toward object or activity (Krapp, 2002).

Furthermore, based on the definition of interest above Krapp (2002), Hidi \& Renniger (2006) and Hidi (2006) described that interest consisted in three parts, there are:

\section{a. Individual (Personal) Interest}

Individual interest is a predisposition of individual characteristic and relatively stable. Individual interest involves knowledge, positive affect and value, and develops slowly over time, and affected by repeated experiences of situational interest. Individual interest also refers to specific topic, object or activity, such interest in reading, interest in sport, interest in specific subject and others.

\section{b. Situational Interest}

Situational interest is an interest fostered by conditions or environmental factors. Most researchers were defined situational interest as an immediate affective response to certain conditions or stimuli in the learning environment that focuses one's attention on the task, which may or may not last over time. For example; 
interest to read books related to the assignment, essay, project paper and thesis and other.

\section{c. Interest as a Psychological State}

Interest as a psychological state is an interplay between personal or individual interests and environmental conditions or situational interest. The process of interest as a psychological state including increased attention, positive effect, concentration, and an increased willingness to learn. For example; a student who has a strong interest to read about human motivation, will show often behavior to read books, journal, essay, magazine, story about motivation, both at home, at school, or at library, the student is psychologically a high interest to read about human motivation.

An addition, Hidi and Renninger (2006) and Hidi (2006) stated that interest can develop through four phases, there are;

1. Situational interest is triggered (started)

2. Situational interest is sustained (continued)

3. Situational interest becomes lessdeveloped individual interest. (more stable dispositional form of interest)

4. Situational interest becomes a welldeveloped individual interest.

Those phase described that basically interest started from stimulus in the environment. When the environment was able to support and give easiness facility in specific topic, object or activity, perhaps situational interest of the student will emerge. Then, when situational interest was continued, situational interest will become more stable and finally will settle as individual interest. Those phases only describe in both of individual and situational interest, but it still important because according to Wigfield et al., (2004), both of situational and individual interest could be supported and influenced learning activities and learning performance of student, because when students have interest to the specific topic, object or activity, perhaps student will create the strategies and will engage themselves to that topic, object or activity (Wigfield, Guthrie, Tonks, \& Perencevich, 2004).

\section{The Aspect of Interest}

Interest grew and developed based on relationship between individual purpose and environmental factor. Therefore, it is important to prepare good environment so that the student will involve, enjoy and tend to possess knowledge base on the topic, object or activity that they interested. Further, Krapp (2002, 2005) and Hidi (2006) stated that have two aspects that contribute to develop interest, there are cognitive and affective aspects (Hidi, 2006; Krapp, 2002, 2005).

\section{a. Cognitive Aspect}

A cognitive aspect refers to personal values and goal. It associated with anything that can be beneficial and lead to personal satisfaction derived from interest. It means interest in cognitive aspects was grow and develop base on prejudice, expectation and conviction that lead to achieve cognitive advantage including values and goals of the topic, object or activity. When student was discovery satisfaction and profit in their object or activity, interest could be permanent, even it will grow stronger. Conversely, if there is no satisfaction and profit in their topic, object or activity, interest could be weakening, or even disappeared (Hidi, 2006; Krapp, 2002, 2005). For example, student has interest to read specific topic, perhaps student will feel confident and spent more time and effort to engage him/her self to do reading activity, because student believe and expect that activity will bring benefits, values and 
personal satisfaction. When the profit and satisfaction were became a reality, interest to read that specific topic could be remain, even it will grow stronger. Conversely, if the satisfaction and benefits of reading activity do not become reality, interest to read specific topic could be weaken or even disappear and be replaced by other topic, object or activity.

\section{b. Affective Aspect}

An affective aspect refers to feeling related to the experience. This aspect emphasized on feelings and personal experiences including the attitude toward people who assumed can influence each others, such as parents, teachers, public figure and friends in social peers. This affective aspect has a greater role in developing interests. It means the affective aspect have tendency to be last longer to change, therefore it is important to consider how to trigger and build the affective aspect as well to develop students interest (Hidi, 2006; Krapp, 2002, 2005). For example, student who has a good model in reading (such as parent, teacher, friends, and peers) and also has good relationship with the model, so perhaps student will follow and engage themselves to do reading activity, and eventually interest to do reading activity will become stronger and develop. Conversely, when student has a bad model and bad experience in reading activity usually student will avoid reading activity and will change it to other topic, object or activity.

\section{The Concept of Reading Motivation}

In a book "A History of Reading” by Manguel (1997) Grayling mentioned that reading as a flight. Its mean when individual was flight, he/she will view over wide of terrains, human variety, ideas, shared experiences and the fruits of many inquiries. That book also explains that through reading, reader can go anywhere to see other world without being limited by dimension of space and time. Reading really will give opportunities to imagine anything in life Therefore, reading was assuming as a tour of mind, because reading able to provide pleasure and enjoyment of the soul. Those explanations described one reason why people sometime can spend more time to do reading activity. However, also not everyone can spend their time to do reading activity.

According to Gambrell \& Marinak (2008) and Guthrie, Wigfield, \& VonStecker (2000), the important role was play in reading is motivation. Motivation is strongly drive that influence individual to engage in specific activity. Therefore, students who have strong motivation to do reading can spend their time so much in reading activity. Meanwhile, students who lack motivation to do reading will try to avoid reading activity (Guthrie, et al., 2000; Marinak \& Gambrell, 2008).

Further, Guthrie et al (2006) and Watkins \& Coffey (2004) mentioned that the concept of reading motivation try to understand why individual choice to do reading activity or not to do. It means, the concept of reading motivation emphasized to mental readiness, willingness and also refers to beliefs and perception of individual to engage in reading activity. Therefore, reading motivation assumed as a complex and multidimensional construct that can be influenced by internal and external factors (Guthrie, Wigfield, et al., 2006; Watkins \& Coffey, 2004). Moreover Wang \& Guthrie (2004) stated that curiosity, preference for challenge, and involvement are internal factors that influence reading motivation. Meanwhile, recognition, competition, and grades considered as external factors (Wang $\&$ Guthrie, 2004). 
Generally, reading motivation divided in two parts; there are intrinsic reading motivation and extrinsic reading motivation. Moreover, Guthrie et al (2006) described that intrinsic reading motivation referred to students' curiosity about new books and topics, immersion in reading for long periods of time, and preference for longer challenging texts. Conversely, extrinsic reading motivation referred to grades or competition as reasons for reading (Guthrie, Hoa, Wigfield, Tonks, \& Perencevich, 2006). However, Deci, Koestner, and Ryan (2001) described that intrinsic reading motivation is guided by a need for self-determination and competence. Meanwhile, extrinsic reading motivation referred to something outside of the individual, such as rewards, deadlines, competitions, goals, or evaluations (Deci, Koestner, \& Ryan, 2001)

Deci, Koestner and Ryan (2001) also stated that increases or decreases intrinsic reading motivation depending on how the event in extrinsic reading motivation is perceived by the individual. When the individual identifies the external reading motivation event as increasing his or her selfdetermination, then the event will in turn increase intrinsic reading motivation. In contrast, when the individual assumed the external reading motivation event as decreasing his or her self-determination, so perhaps it will decrease reading motivation of individual (Deci, et al., 2001). Therefore, Gambrell \& Marinak (2008) and Guthrie et al (2000) stressed motivation as a key for doing reading activity, because without reading motivation to read, students may never reach their full potential in their learning (Guthrie, et al., 2000; Marinak \& Gambrell, 2008).

\section{The Factors that Influence Reading Motivation}

Reading motivation is a combination of some factors that leads student to make or not make the decision to read. Guthrie et al (2006) stated that student who engage in reading activity is has motivated to read. Further, Guthrie et al (2006) described that engage reader have a motivation to do reading activity, including involvement, curiosity, and social aspects, but not necessarily compliance for an assignment (Guthrie, Hoa, et al., 2006).

According to researches under reading motivation, researchers were identified some factors that influenced reading motivation of students. Various studies indicate that basically reading motivation is influenced by the complex interaction of intrinsic and extrinsic factors. Some study, such as Wang \& Guthrie (2004) Watkins \& Coffey (2004) and Deci, Koestner \& Ryan (2001) described that students were motivated to read by different factors, but interrelated causes (Deci, et al., 2001; Wang \& Guthrie, 2004; Watkins \& Coffey, 2004). Additionally, they also stated that reading efficacy, challenge, curiosity, involvement, grades, importance, recognition, compliance, competition, social, and work avoidance all serve as constructs that effect reading motivation (Deci, et al., 2001; Wang \& Guthrie, 2004; Watkins \& Coffey, 2004). Moreover, Wigfield et al (2004) and Guthrie et al (2007) identified reading efficacy, curiosity, and involvement as factors that are attributed to intrinsic reading motivation. Meanwhile the remaining constructs of recognition, grades, and compliance were considered to be extrinsic sources of reading motivation (Guthrie, et al., 2007; Wigfield, et al., 2004).

Further, some researchers such as Pecjak \& Peklaj (2006), Durik, Vida \& Eccles (2006), and Marinak \& Gambrell (2010) have identified a number of important factor that influenced reading motivation, there are selfconcept and value of reading, choice including time spent talking about books, types of text available, and the use of incentives (Durik, Vida, \& Eccles, 2006; 
Edmunds \& Bauserman, 2006; Marinak \& Gambrell, 2010; Pecjak \& Peklaj, 2006). However, Merisuo-Storm (2006) Guthrie et al (2006) and Guthrie \& Cox (2001) mentioned that actually have another factor that influences reading motivation there is interest. They found that interest should be a key factor in the selection of reading material (Cox \& Guthrie, 2001; Guthrie, Hoa, et al., 2006; Merisuo-Storm, 2006). This argument also supported by Krapp (2005) and Hidi (2006) who mentioned that interest is a factor of intrinsic motivation to do reading activity (Hidi, 2006; Krapp, 2005).

Moreover, Krapp (2005) and Hidi (2006) described that interest includes both of personal interest and situational interest. Personal interest includes feeling-related beliefs toward a text in a certain content domain, such as excitement, stimulation and flow. Meanwhile, situational interest involves a temporary state elicited by certain features of a text (Hidi, 2006; Krapp, 2005). Additionally, Edmunds \& Bauserman (2006) also described that when the book related to personal interest, the book will gain knowledge, and the book characteristic appealed to student, so perhaps individual will have motivation to read and it's also as some reason why student choice to engage to do reading activity (Edmunds \& Bauserman, 2006).

\section{Conclussion}

According to the literatures review about interest and reading motivation above, I can concluding that basically interest and reading motivation has positive relationship. It means, interest could be influence reading motivation of students, and when students have higher interest, students also will show higher reading motivation.

This assumption based on theory by krapp (2002), Renninger et al (2002), Hidi \& Renninger (2006) and Hidi (2006) who described interest as a unique motivational variable and as a psychological state that occurs during interaction between individual and objects or activity that their interest. In this interaction including a process of willingness to engage on specific object or activity, and in this process also characterized by increased attention, concentration and positive affects to the topic, object or activity (Hidi, 2006; Hidi \& Renninger, 2006; Krapp, 2002; Renninger, et al., 2002). It means, in this context when students have interest to do reading activity, student will show more active participation including willingness, attention, concentration and happiness to do reading activity. Conversely, when students do not have interest to do reading activity, students will avoid that activity.

This assumption also supported by Merisuo-Storm (2006) Guthrie et al (2006) and Guthrie \& Cox (2001), who mentioned that interest variable was influenced reading motivation. They found in their study that interest should be a key factor in the selection of reading material (Cox \& Guthrie, 2001; Guthrie, Hoa, et al., 2006; Merisuo-Storm, 2006). Further, Krapp (2005) and Hidi (2006) also supported this argument. They stated that interest is a intrinsic motivation factor for individual to do reading activity (Hidi, 2006; Krapp, 2005).

Moreover, Edmunds \& Bauserman (2006) also described how personal interest could be influence reading activity based on the book that they read. They explained that when the book related to the personal or individual interest, the book will assume as predisposition to gain knowledge, so student will read that book with willingness and happiness and eventually the characteristic of the book will emerge motivation to read (Edmunds \& Bauserman, 2006). Those explanations also portrayed and supported that interest variable related to the reading motivation variable. 
So, in general writer can conclude that actually have positive relationship between interest and reading motivation based on the literature review. However, this assumption have to investigate and examine deeply, such as delivered this issue to the real research, so perhaps the relationship between both of those variable could be seen distinctively.

\section{Implication}

The purpose of this study is to examine the relationship between interest and reading motivation based on literature review. And the literature review described that basically both of those variable have positive relationship. It means, generally this study has big impact for improving learning performance of students.

In specific, this study described how the role of interest for enhancing attention, concentration, willingness and positive feeling of students to do them activity that related to the learning and in this context specific to reading activity. So, when the students have willingness to do reading, and it following by high attention, concentration and happiness, perhaps students will achieve more knowledge and information. It mean, perhaps students will get maximum achievement in their academic activity. However, for triggering and emerging student interest need work hardly by educators and teachers, because according to Krapp (2002), Hidi \& Renniger (2006) and Hidi (2006), interest triggered based on situational interest and then mobile to individual interest and finally will become as psychological state (Hidi, 2006; Hidi \& Renninger, 2006; Krapp, 2002). It mean, the educational institution including school context as an environmental factor have big impact to trigger and emerge the situational interest of student. Therefore, educators and teachers have to consider it to build appropriate and comfortable environment that supported to trigger and emerge situational interest of student.

Additionally, in relation to the reading activity, educators and teachers have to consider and pay attention to the environment that supported to trigger and emerge reading activity, such as provided comfortable library, easier to enter and access library, enlarge reading room, easier for searching books, journals and materials, enrich the references etc. So, when the external factors (environment) supported to trigger and to emerge situational interest of students, perhaps it will mobile to individual interest and finally reading will become psychological state of interest. In this stage, perhaps students will have high reading motivation, because they know and aware that reading will give them more advantages for increasing their knowledge and for getting success in the future.

Further, the implication of this study also related to the educators, teachers, school staffs, parents, family or people who are a model or public figure for students or children. In this context, all of them have contributed to trigger and emerge the interest of students or children, because according to Krapp (2002, 2005) and Hidi (2006) students or children who have good models in reading and followed by good relationship with their model generally will engage themselves to follow their model, in this context is reading. Therefore, educators, teachers, school staffs, parents, family or people who are a model or public figure suggested to become good model in reading and also suggested to build good relationship to their students or children, so that eventually perhaps will improve reading motivation of students or children as well, and will enhance learning performance of students or children. 


\section{References}

Ainley, M., Hillman, K., \& Hidi, S. (2002). Gender and interest processes in response to literary texts: situational and individual interest. Learning and Instruction, 12, 411-428.

Aksan, N., \& Kisac, B. (2009). A descriptive study: Reading comprehension and cognitive awareness skills. Procedia Social and Behavioral Sciences, 1, 834-837.

Alexander, P. A., \& Wade, S. E. (2000). Contexts that promote interest, selfdetermination, and learning: lasting impressions and lingering questions. Computers in Human Behavior, 16, 349-358.

Cox, K. E., \& Guthrie, J. T. (2001). Motivational and Cognitive Contributions to Students' Amount of Reading. Contemporary Educational Psychology, 26, 116-131.

Deci, E. L., Koestner, R., \& Ryan, R. M. (2001). Extrinsic rewards and intrinsic motivation in education: Revisited once again. Review of Educational Research, 7(1), 1-27.

Durik, A. M., Vida, M., \& Eccles, J. S. (2006). Task values and ability beliefs as predictors of high school literacy choices: A developmental analysis Journal of Educational Psychology, 98(2), 392-393.

Edmunds, K. M., \& Bauserman, K. L. (2006). What Teachers Can Learn About Reading Motivation Through Conversations With Children. The Reading Teacher, 59(5), 414-424.

Guthrie, J. T., Hoa, A. L. W., Wigfield, A., Tonks, S. M., Humenick, N. M., \& Littles, E. (2007). Reading motivation and reading comprehension growth in the later elementary years.
Contemporary

Educational

Psychology, 32, 282-313.

Guthrie, J. T., Hoa, L. W., Wigfield, A., Tonks, S. M., \& Perencevich, K. C. (2006). From spark to fire: Can situational reading interest lead to long-term reading motivation? Literacy Research and Instruction, 45(2), 91-117.

Guthrie, J. T., Wigfield, A., Humenick, N. M., Perencevich, K. C., Taboada, A., \& Barbosa, P. (2006). Influences of Stimulating Tasks on Reading Motivation and Comprehension. The Journal of Educational Research, 99, 232-245.

Guthrie, J. T., Wigfield, A., \& VonSecker, C. (2000). Effects of integrated instruction on motivation and strategy use in reading Journal of Educational Psychology, 92(2), 331-341.

Hidi, S. (2006). Interest: A unique motivational variable. Educational Research Review, 1, 69-82.

Hidi, S., \& Renninger, K. A. (2006). The four-phase model of interest development. Educational Psychologist, 41, 111-127.

Krapp, A. (2002). Structural and dynamic aspects of interest development: theoretical considerations from an ontogenetic perspective. Learning and Instruction, 12, 383-409.

Krapp, A. (2005). Basic needs and the development of interest and intrinsic motivational orientations. Learning and Instruction, 15, 381-395.

Manguel, A. (1997). A History of Reading; The New York Time Book Review

Marinak, B. A., \& Gambrell, L. B. (2008). Intrinsic Motivation and Rewards: What Sustains Young Children's Engagement with Text? Literacy Research and Instruction, 47, 9-26. 
Marinak, B. A., \& Gambrell, L. B. (2010). Reading Motivation: Exploring the Elementary Gender Gap. Literacy Research and Instruction, 49(2), 129141.

McWhaw, K., \& Abrami, P. C. (2001). Student Goal Orientation and Interest: Effects on Students' Use of SelfPecjak, S., \& Peklaj, C. (2006). Dimensions of reading motivation and reading achievement in 3rd and 7th grade students. Studia Psychologica, 48(1), 11-30.

Pintrich, P. R., \& Schunk, D. H. (1996). Motivation in Education; Theory, Research, and Applications. . Engglewood Cliffs: Preatice-Hall.

Renninger, K. A., Ewen, L., \& Lasher, A. K. (2002). Individual interest as context in expository text and mathematical word problems. Learning and Instruction, 12, 467-491.

Schiefele, U., \& Krapp, A. (1996). Topic interest and free recall of expository text. learning and Individual Diflerences, 8(2), 141-160.

Strommen, L. T., \& Mates, B. F. (2004). Learning to love reading: Interviews with older children and teens. Journal of Adolescent \& Adult Literacy, 48, 188-200.

Tin, T. B. (2006). Investigating the nature of 'interest' reported by a group of postgraduate students in an MA in
Regulated Learning Strategies. Contemporary Educational Psychology, 26, 311-329.

Merisuo-Storm, T. (2006). Girls and Boys Like to Read and Write Different Texts. Scandinavian Journal of Educational Research, 50(2), 111125.

English language teacher education programme. System 34, 34, 222-238.

Valleley, R. J., \& Shriver, M. D. (2003). An examination of the effects of repeated readings with secondary students. Journal of Behavioral Education, 12, 55-76.

Wang, J. H. Y., \& Guthrie, J. T. (2004). Modeling the effects of intrinsic motivation, extrinsic motivation, amount of reading, and past reading achievement on text comprehension between U.S. and Chinese students. Reading Research Quarterly, 39, 162186.

Watkins, M. W., \& Coffey, D. Y. (2004). Reading Motivation: Multidimensional and Indeterminate. Journal of Educational Psychology, 91(1), 110-118.

Wigfield, A., Guthrie, J. T., Tonks, S., \& Perencevich, K. C. (2004). Children's motivation for reading: domain specificity and instructional influences. Journal of Educational Research, 97, 299-309., 97, 299-309. 